\title{
ORGANIZAÇÃO E PLANEJAMENTO DE ESTÁGIOS
}

\author{
Maria Lourdes $\mathrm{Gisi}^{1}$ \\ Maria Antonia M. Schwartz ${ }^{2}$ \\ Neuza Baptista Gomide ${ }^{3}$ \\ Vera Lúcia Casteleins ${ }^{4}$ \\ Elizandra Simone Alves ${ }^{5}$
}

\section{Resumo}

O presente trabalho refere-se a primeira etapa da pesquisa realizada em uma Instituição de Ensino Superior sobre a organização e o planejamento dos estágios curriculares. $\mathrm{O}$ interesse em abordar essa questão decorre das novas exigências que se colocam hoje para o ensino superior de propiciar uma formação profissional condizente com as rápidas transformações sociais. Neste contexto observa-se uma tendência em oportunizar aos alunos, desde 0 início do curso, situações de aprendizagem em contexto real de trabalho, um panorama diferenciado na organização curricular com os quais se defrontarão os alunos no decorrer de sua formação. Nessa perspectiva foi proposta uma investigação com o objetivo de: caracterizar os estágios na instituição, Identificar a sua organização e planejamento e analisar os significados atribuídos ao estágio no processo de formação. Para atingir os objetivos propostos foi realizado inicialmente um estudo exploratório junto aos Diretores de Curso e professores supervisores de estágio, utilizando-se o questionário como instrumento de coleta de dados. Os resultados evidenciaram a necessidade de definição de diretrizes institucionais para os estágios e maior aprofundamento na

\footnotetext{
${ }^{1}$ Doutora em Educação, Prof ${ }^{a}$ do Programa de Pós-Graduação em Educação.

${ }^{2}$ Prof ${ }^{\mathrm{a}}$ Adjunto 3 da PUCPR. Mestre em Educação

${ }^{3}$ Prof ${ }^{\text {a }}$ Adjunto 3 da PUCPR. Mestre em Educação

${ }^{4}$ Profa ${ }^{-}$Assistente 1 da PUCPR. Mestre em Educação

${ }^{5}$ Acadêmica do Curso de Pedagogia da PUCPR
} 
compreensão do estágio como momento privilegiado da relação teoria/prática presente em todo processo de formação. As possibilidades de o estágio constituir-se em uma estratégia que favoreça a aquisição de aptidões, competências e habilidades definidas para o curso, pressupõe considerá-lo como parte integrante e essencial do processo de formação devendo ser planejado de modo a proporcionar experiências de aprendizagem dinâmicas, criativas e que possibilitem a reflexão sobre a atuação profissional e a sua intencionalidade.

\section{Pa lavras-chave:}

Estágio, currículo, processo de formação

\section{Intơduçã o}

O presente trabalho tem como ponto de partida as indagações que permeiam a organização, o planejamento e o desenvolvimento dos estágios curriculares. Tal opção encontra sua razão de ser no fato de que os estágios vêm assumindo maior importância diante das novas exigências de formação de profissionais aptos a darem respostas às rápidas transformações sociais. Neste contexto verifica-se uma tendência em ofertar os estágios curriculares desde o primeiro ano do curso de graduação acompanhando todo processo de formação em crescente complexidade.

Esta orientação não constitui fato novo, pois desde a década de 1980 vem se discutindo, mediante realização de seminários regionais e nacionais, a importância dos estágios como uma modalidade de ensino que não deveria ser ofertada tão somente no final do processo de formação, como ainda ocorre em muitos cursos. Como afirma Salgado: "Em primeiro lugar, não tem qualquer fundamento a idéia de que o teórico antes do prático, o analítico antes do sintético, o disciplinar antes do interdisciplinar são a ordem natural das coisas e do ensino" (Salgado, 1993, p.18). Este autor propõe mais do que isto, que os estágios se constituam em eixo norteador da estruturação curricular: “ $\{. .$.$\} programar o estágio de início ao fim do curso e até mesmo estruturar 0$ currículo através de uma seqüência orgânica de estágios." (Salgado, 1993, p.19).

Tais idéias indicam a importância de os estágios serem ofertados no decorrer dos cursos, superando a idéia de estágio como etapa complementar de aplicação da teoria. Isto se justifica porque o estudo dos fenômenos no contexto em que estes ocorrem, favorece a sua compreensão e coloca o estudante em confronto com situações reais possibilitando o desenvolvimento de competências necessárias para sua formação profissional.

O estágio curricular, como uma experiência pré-profissional e vincu- 
lada aos objetivos do processo de aprendizagem, poderá propiciar tanto a competência técnico-científica, quanto a compreensão das implicações do trabalho no contexto das relações sociais. Portanto, não é tão somente exercício pré-profissional, ou uma atividade prática qualquer mas é fundamentalmente um espaço que poderá propiciar além do saber-fazer específico de sua área de formação também o desenvolvimento da criatividade, da autonomia, da ética e da solidariedade quando os alunos, ao se confrontarem com situações reais, nelas intervêm, sob a supervisão de professores e profissionais do campo de estágio.

No entanto, para que se concretize o estágio como espaço de formação do profissional cidadão é necessário compreendê-lo contextualmente, isto é, a partir do currículo no qual está inserido, que por sua vez, deve ser decorrente da política definida pela Instituição para o ensino da graduação. Embora tenha especificidades no que se refere a sua operacionalização, a sua discussão, organização, planejamento só poderá se dar no bojo da proposição dos projetos pedagógicos dos cursos de graduação.

A visão de totalidade da formação profissional deve prever a necessária articulação entre o saber e o fazer, a reflexão e a ação, o individual e 0 social concretizados no âmbito das relações sociais (Gisi; Schwartz, 1999).

Pensar sobre a dimensão formadora e social dos estágios pressupõe questionar qual profissional se quer formar para qual sociedade, definindo o perfil e as competências a serem buscadas no processo de formação e portanto, no estágio curricular supervisionado.

As constantes mudanças impostas pela sociedade atual estão causando profundos impactos no processo de formação, exigindo mudança dos paradigmas que vinham norteando a concepção de formação profissional nas universidades. A ênfase nas especializações dá lugar à formação integral do homem numa concepção holística. O ensino centrado nos conteúdos, por sua vez, é substituído pelo enfoque na aprendizagem de competências necessárias para atuar no âmbito da área profissional escolhida. Mais do que acumular informações o aluno deverá aprender a aprender, aprender a fazer, aprender a ser e aprender a conviver, que compõem os quatro pilares da educação propostos pela UNESCO conforme Delors (1996).

Tais mudanças no enfoque da aprendizagem terão que ser considerados na organização, planejamento e desenvolvimento dos estágios e certamente são estes estágios que favorecem melhor que qualquer experiência de aprendizagem o desenvolvimento das competências definidas em cada curso, pois, confrontam o aluno com situações reais do campo profissional.

Entretanto nem sempre os estágios contribuem para o desenvolvimento das competências desejadas e necessárias devido a dificuldades existentes. Tais dificuldades podem ser atribuídas tanto à organização e ao planejamento como ao próprio desenvolvimento, o que decorre principalmente da 
falta de aprofundamento das discussões sobre o estágio no contexto do curso no qual se insere.

Outro aspecto a ser considerado refere-se à existência de diretrizes institucionais que possam nortear a organização e o planejamento dos estágios, quando inexistentes, levam a realização de estágios desvinculados do projeto pedagógico institucional.

Cabe ressaltar também, que existem ainda dificuldades decorrentes das relações entre a instituição de ensino e os campos de estágio quando não há efetivamente um planejamento conjunto e definição clara dos papéis do professor supervisor e do profissional do campo de estágio.

Diante das dificuldades levantadas questiona-se até que ponto os estágios curriculares, tais como vêm sendo desenvolvidos na instituição, contribuem para a formação pretendida, expressa em termos do perfil, aptidões, competências e habilidades?

Considera-se portanto, fundamental a realização de um estudo investigativo sobre os estágios, de forma a propiciar subsídios para os cursos que se encontram em processo de implantação dos seus projetos pedagógicos.

A investigação contínua dos estágios curriculares é tarefa prioritária para que se possam tomar decisões criativas e inovadoras que levem ao aprimoramento da formação profissional pretendida.

\section{Objetivos}

- Caracterizar os estágios curriculares dos Cursos de Graduação;

- Identificar as formas de organização e planejamento dos estágios na Instituição;

- Analisar o significado atribuído ao estágio no processo de formação profissional;

- Oferecer subsídios para a definição de diretrizes e normas institucionais para os estágios na PUCPR.

\section{Metodologia}

Diante da intenção de avaliar os estágios curriculares em relação ao perfil do profissional desejado no processo de formação, este trabalho parte do pressuposto de que nas instituições de modo geral cultivam-se modos de ação e produz-se uma cultura própria, que precisa ser conhecida e interpretada para que possam ocorrer mudanças. 
Conforme indica Brunet "as organizações escolares ainda que estejam integradas num contexto cultural mais amplo, produzem uma cultura interna que lhes é própria e que exprime os valores (ou os ideais sociais) e as crenças que os membros da organização partilham". ( Apud. Nóvoa , 1992 p. 29 )

Estes diferentes elementos da cultura institucional, de acordo com Nóvoa (1992), tem importante papel nas interações que se estabelecem com a comunidade, isto é a forma como nos relacionamos com os campos de estágio e com os alunos que se encontram em processo de formação profissional.

Outro aspecto a ser considerado se refere à pesquisa que será realizada em uma instituição de ensino o que lhe confere características especiais. Quando se fala em instituição, está se falando da coisa estabelecida e pode nos dar a impressão inicial de dificuldade em proceder qualquer mudança, mas como afirma Barbier (1985) se estabelecida pelos homens também está sujeita a transformação.

A intenção de não só conhecer e interpretar a realidade, mas de propiciar transformações na concepção e organização dos estágios é que levou o grupo de pesquisados a optar por uma pesquisa - ação.

A pesquisa ação é um tipo de pesquisa social, com base empírica, destinada ao estudo e à intervenção em situações reais visando contribuir para interesses práticos de pessoas em uma situação - problema específico (Ludke, 1991). Tal pesquisa propicia ao grupo de pesquisadores e supervisores de estágio, um processo de reflexão - ação - reflexão, na superação dos obstáculos para uma nova prática comprometida com a formação profissional pretendida.

São, portanto, os diretores de cursos e os professores supervisores de estágio que se constituem em sujeitos desta pesquisa.

Para o desenvolvimento da pesquisa foram previstas cinco fases:

1ํㅡㄹ fase: refere-se ao diagnóstico sobre a concepção e organização dos estágios dos diferentes cursos da Universidade.

Nesta fase foi utilizado como instrumento de pesquisa um questionário com perguntas abertas e fechadas que foi aplicado pelo grupo de pesquisadores no local de atuação dos participantes da pesquisa. Os tópicos investigados foram:

a) caracterização dos estágios ;

b) organização, planejamento e desenvolvimento do estágio sional.

c) significado atribuído ao estágio no processo de formação profis-

O instrumento de pesquisa foi submetido ao julgamento de especialistas (professores da área da educação ) de modo a torná-lo adequado aos 
objetivos propostos para o estudo. Os questionários foram encaminhados aos Diretores de Curso num total de 40 retornando 24 e aos professores supervisores de estágio num total de 150 retornando 85. O prazo de devolução foi de um mês e meio. A partir desta $1^{a}$ fase serão organizados seminários com participação do grupo de pesquisadores e professores supervisores de estágio. A opção pela realização de seminários se dá no entendimento de que a própria participação é considerada como método de aprendizagem para uma nova prática na medida que propicia a reflexão sobre o cotidiano da ação docente.

2 a fase: será iniciada com base nos dados de fase diagnóstica quando os resultados da pesquisa são apresentadas aos sujeitos do estudo; caracterizase, pois, pela discussão coletiva, contribuição da experiência vivenciada, participação efetiva dos professores supervisores.

3a fase: refere-se á reflexão teórica sobre a prática pedagógica que eu tenho e a prática pedagógica que eu gostaria de ter para tornar o estágio efetivamente uma experiência de ensino que contribua para a formação do profissional desejado.

4⿳一巛工 fase: refere-se a construção da proposta de estágio pelos professores supervisores, proposta esta que se constitui em parte integrante do projeto pedagógico dos cursos.

5a fase: Proposição de diretrizes e normas institucionais para os estágios tomando-se como base o resultado das análises e discussões das fases anteriores.

Como já foi mencionado, este trabalho apresenta os resultados decorrentes da primeira fase e constitui um diagnóstico sobre a organização e planejamento dos estágios dos diferentes Cursos de Graduação da Universidade.

Esta fase pode ser caracterizada como um estudo exploratório e teve o intuito de aumentar o conhecimento das autoras em torno do problema e encontrar elementos necessários para uma aproximação com os sujeitos professores supervisores de estágio. De acordo com Marconi e Lakatos, os estudos exploratórios " $\{. .$.$\} são investigações de pesquisa empírica cujo objeti-$ vo é a formulação de questões ou de um problema com tripla finalidade: desenvolver hipóteses, aumentar a familiaridade do pesquisador com o ambiente, fato ou fenômeno para realização de um pesquisa futura mais precisa ou modificar e clarificar conceitos" (1999, p. 87).

Este estudo buscou uma maior familiaridade com o fenômeno em estudo e utilizou um procedimento específico para a coleta de dados: o questionário com questões abertas e fechadas. 
Os resultados obtidos com a aplicação dos questionários junto a diretores de curso e professores supervisores de estágio foram analisados à luz da técnica de análise de conteúdo. Segundo Bardin se considerarmos o objetivo, o terreno e o funcionamento da análise de conteúdo, esta pode ser designada como:

Um conjunto de técnicas de análise das comunicações visando obter, por procedimentos sistemáticos e objetivos de discussão do conteúdo das mensagens, indicadores (quantitativos ou não) que permitam a inferência de conhecimentos relativos às condições de produção e recepção destas mensagens" (Bardin, 1995, p.42).

Neste estudo buscou-se descobrir os núcleos de sentido presentes nas respostas cuja frequência tinham significado para o objeto da investigação. A preocupação em considerar a frequência das respostas baseou-se na premissa de que a importância de uma unidade de registro aumenta com a freqüência da sua aparição. Tal frequencia, no entanto, não ficou restrita à quantificação das respostas por questão, mas ao conteúdo das mensagens na sua globalidade. A partir das afirmativas sobre determinado tema foram feitos recortes de unidades de análise gerando categorias.

\section{Resultados}

A presente pesquisa teve início com o levantamento de informações sobre os diversos cursos existentes na Instituição. A partir deste momento foram elaborados os questionários, utilizados como instrumentos da pesquisa e deu-se início ao processo de coleta de dados.

Com os questionários já em mãos a equipe de pesquisadores iniciou a análise dos dados conforme apresentado a seguir:

\subsection{Resultados obtidos junto a Diretores de Curso}

Os dados obtidos junto aos Diretores de Curso indicam que os estágios, embora considerados importantes, requerem uma atenção especial por parte da Instituição, pois, evidencia-se uma carga horária insuficiente, oferta em períodos finais do curso configurando-lhes um caráter de complementaridade.

O contato desde o início do curso com a realidade profissional é fundamental para a formação desde que organizado em crescente complexidade acompanhando o desenvolvimento do currículo. $O$ estágio permite também que se façam reavaliações constantes do currículo proposto em decor- 
rência das exigências do mercado e das necessidades sociais. Outro aspecto que merece reflexão é a não oferta de estágio obrigatório por alguns cursos conforme representado na Tabela 1.

Verifica-se na tabela 1 que 79,16\% dos cursos ofertam estágios obrigatórios, no entanto a existência de 20,84\% de cursos sem estágio obrigatório é um dado preocupante, pois não se possibilita ao aluno a vivência de experiências em ambiente real de trabalho.

\section{Tabela 1 -Demonstrativo da Oferta de Estágios na Institu içã o}

\begin{tabular}{l|c|c}
\hline Oferta de Estágio & No & \% \\
\hline $\begin{array}{l}\text { Cursos que ofertam } \\
\text { estágio obrigatório }\end{array}$ & 34 & 70,83 \\
\hline $\begin{array}{l}\text { Cursos que ainda não } \\
\text { ofertam estágio por estarem } \\
\text { iniciando suas atividades }\end{array}$ & 04 & 8,33 \\
\hline $\begin{array}{l}\text { Cursos que não ofertam } \\
\text { estágio obrigatório }\end{array}$ & 10 & 20,84 \\
\hline TOTAL & $\mathbf{4 8}$ & $\mathbf{1 0 0 \%}$ \\
\hline
\end{tabular}

\section{Quado 1 - Justifica tivaS espemtadAS pelos Reitores de Curso em ellação a Insuficiência da gâar Horária De Está gio}

\section{JUSTIFICATIVA}

- Mercado de trabalho exige carga horária maior.

- Não atende as necessidades de formação acadêmica e do campo de estágio.

- Insuficiente para elaboração e desenvolvimento de projetos, de trabalhos e pesquisas.

- Insuficiente e somente no final do curso. 
O estágio permite confrontar a formação do acadêmico com o exercício da profissão na qual irá atuar, possibilitando assim analisar de forma significativa se o trabalho pedagógico promove o desenvolvimento de profissionais capazes de atuar social e intelectualmente na futura realidade profissional.

\section{Quado 2 - Contribuições do Estágio peranaliração do Currículo segundo a opinião doestodis de Curso}

\section{FORMAS DE CONTRIBUIÇÃO}

- Feedback obtido das empresas que recebem estagiários.

- Dificuldades apresentadas pelos alunos estagiários.

- Possibilidade de conhecer novos procedimentos na área profissional.

- Reuniões realizadas entre os professores que atuam nas disciplinas teóricas e os que atuam nas disciplinas de estágio.

- Resultados de avaliação dos alunos estagiários.

- Relatos de vivências em campo de estágio pelos alunos.

O estágio é considerado pelos Diretores de Curso como importante instrumento para reavaliar o processo pedagógico. Sabe-se, no entanto, que esta reavaliação só ocorre quando os resultados da avaliação dos alunos, as dificuldades apresentadas pelos alunos e as manifestações dos profissionais do campo são efetivamente tomados como indicadores para a melhoria do curso.

\section{Resultados obtidos junto a oof fasoes supervises}

Os resultados evidenciaram que os estágios são considerados de fundamental importância para a formação profissional, no entanto, de acordo com a grande maionia dos professores supervisores, participantes deste estudo, a carga horária e a sua oferta em final de curso dificultam o processo de ensino/ aprendizagem. Além desta questão indicam dificuldades relacionadas à Instituição de ensino, ao campo de estágio e aos alunos. Verificou-se também que o planejamento e a organização dos estágios são bastante diversificados em parte pela especificidade dos cursos mas também em decorência da existência de diferentes concepções de estágio no processo de formação profissional. Da análise das respostas foi possível identificar as seguintes categorias: 


\begin{tabular}{|c|c|}
\hline CATEGORIAS & SUB-CATEGORIAS \\
\hline CONCEPÇÃO DE ESTÁGIO & $\begin{array}{l}\text { Vivência da realidade } \\
\text { Planejamento do estágio } \\
\text { Relação teoria/prática } \\
\text { Reavaliação curricular }\end{array}$ \\
\hline DIRETRIZES INSTITUCIONAIS & $\begin{array}{l}\text { Relação universidade/empresa } \\
\text { Diretrizes para o ensino superior }\end{array}$ \\
\hline
\end{tabular}

\section{A - Concepção de Estágio}

\section{Quadn 1 - Causas da Insuficiência dăaCłrorária de Estágios}

\begin{tabular}{|c|r|}
\hline \multicolumn{1}{|c|}{ CAUSAS } & No \\
\hline - Organização curricular inadequada & 16 \\
- Excesso de estagiários por professor & 2 \\
- Fragmentação curricular & 2 \\
\hline TOTAL & $\mathbf{2 0}$ \\
\hline
\end{tabular}

A principal questão que aparece no Quadro 1 refere-se a organização curricular inadequada, que aponta para a oferta de estágios só no final do curso e principalmente para uma carga reduzida se comparada com a carga total do curso.

Algumas respostas ilustram esta situação:

"Porque o tempo é escasso e deveria ter início antes do ultimo ano." no ultimo ano."

" Porque (a carga horária) é mal distribuída, não poderia ocorrer só

Outra dificuldade apontada refere-se ao número excessivo de estagiários por professores, prejudicando o processo de aprendizagem e excessiva fragmentação curricular e, por conseqüência, estágios com poucas horas sem possibilidade de aproveitamento adequado. 


\section{Quado 2 - Peaepção dos Bfessoes quanto ao Estágio Oportunizar vivência a cotidianfísqional}

\begin{tabular}{|c|c|}
\hline PERCEPÇÕES & No \\
\hline - Insuficiente para vivenciar a realidade & 54 \\
- Propicia vivência de diferentes campos de atuação & 27 \\
- Favorece a relação teoria x prática & 4 \\
\hline TOTAL & $\mathbf{8 5}$ \\
\hline
\end{tabular}

Quando perguntados sobre a carga horária dos estágios, 54 Professores Supervisores consideraram que a mesma é insuficiente não possibilitando vivenciar a realidade profissional conforme pode ser percebido em algumas respostas:

“ 105 horas são absolutamente insuficien tes devido à quantidade de informações e percepções que o aluno só pode adquirir de fato no ambiente de um laboratório de análises clínicas"

" Precisaria no mínimo o dobro do tempo para uma visão real."

" Não permite entrosamento do grupo para planejar e não fornece o conhecimento da realidade."

Os professores consideram que alguns campos de estágio são bastante restritos não oportunizando vivência profissional e que o estágio proporciona apenas uma visão rápida do campo profissional enquanto outros indicam que não há relação do currículo dos cursos com o cotidiano profissional. Consideram também que é carga horária insuficiente para que os alunos possam desenvolver um trabalho mais elaborado relacionando teoria à prática:

"É impossível formar um profissional com coerência e consistência."

"Apenas propicia visão geral da profissão e não um posicionamento diante dos problemas identificados."

Dos professores supervisores respondentes vinte e sete (27) consideram o estágio como vivência dos diferentes campos de atuação enquanto que quatro (4) professores justificam a importância do estágio como o momento de relacionar a teoria à prática. 
"O projeto profissional, organizado sob a orientação dos professores supervisores, alia teoria à prática possibilitando conhecimento da realidade em que vai atuar."

\section{Quado 3 - Tpo de orientação inicial dada aos estagiários pelos pofessoes supervises}

\begin{tabular}{|l|c|}
\hline TIPO DE ORIENTAÇÃO & No \\
\hline Planejamento/programação do estágio do estágio & 25 \\
Normas de Estágio (manual) & 21 \\
Etapas do estágio & 7 \\
Base teórico-prática sobre estágios & 7 \\
Apresentação do campo de estágio & 3 \\
Orientação de acordo com a atividade desenvolvida & 2 \\
Seleção do campo de estágio com antecedência & 2 \\
Legislação e conscientização sobre importância do estágio & 1 \\
Relação do estágio com o trabalho científico & 1 \\
\hline TOTAL & $\mathbf{7 0}$ \\
\hline
\end{tabular}

Dos professores supervisores respondentes vinte e cinco (25) destacam a importância de o aluno tomar conhecimento de um planejamento/ programação de estágio. Vinte e um (21) professores fornecem um manual contendo as normas de estágio no que se refere "à metodologia, objetivos do estágio, proposta de trabalho.

Quatorze (14) professores supervisores apresentam aos alunos as etapas do estágio "...de forma expositiva, orientado-os sobre os procedimentos e normas de funcionamento dentro do campo de estágio."

Sete (07) professores fornecem base teórico/prática sobre os estágios.

Verifica-se ainda que há preocupação em selecionar campo de está- 
gio adequado, levar o aluno a conhecer o campo, orientá-lo sobre a legislação existente e sobre a importância desta prática.

\section{Quado 4 - planejamento de estágio pelos alunos}

\begin{tabular}{|l|c|}
\hline PLANEJAMENTO DO ESTÁGIO & No \\
\hline $\begin{array}{l}\text { Elaboram plano de trabalho ou } \\
\text { planejamento de atividades ou projeto } \\
\text { de estágio }\end{array}$ & 36 \\
Não fazem planejamento & 28 \\
Não responderam & 21 \\
\hline TOTAL & $\mathbf{8 5}$ \\
\hline
\end{tabular}

Trinta e seis (36) professores referem que o aluno faz algum tipo de planejamento como plano de trabalho ou planejamento de atividades ou projetos "observando algumas normas técnicas e apresentando justificativa, objetivos, fundamentação teórica, procedimentos, recursos, cronograma, referências bibliográficas."

"É um planejamento que irá nortear o estágio durante o ano inteiro."

Dos professores supervisores respondentes, vinte e oito (28) afirmaram que os alunos não fazem planejamento de estágio. Nestes casos o aluno acaba realizando o que aparece ou o que o campo solicita, o que pode não corresponder às necessidades de aprendizagem. 


\section{Quadø 5 - Fomas de favecer a clação Toria x Prática nos estágios}

\begin{tabular}{|l|c|}
\hline FORMAS DE RELAÇÃo TEORIA PRÁTICA & No \\
\hline Relação Teoria x Prática é oportunizada nos estágios & 37 \\
Realização de seminários/relatórios/ Apresentações & 18 \\
Estudo de caso & 4 \\
Existência de relação teoria/prática no decorrer do curso & 4 \\
Vivência profissional laboratorial & 4 \\
Não há relação Teoria x Prática & 4 \\
Levantamento de necessidades da realidade & 2 \\
Reuniões periódicas & 2 \\
Atuação clínica & 1 \\
\hline TOTAL & $\mathbf{7 6}$ \\
\hline
\end{tabular}

Dos professores supervisores respondentes, trinta e sete (37) afirmaram que a relação teoria x prática se faz presente no estágio mas não justificaram suas respostas. Dezoito (18) professores realizam discussões, aulas práticas, reuniões, seminários, apresentações com "relato da parte teórica de cada caso."

As demais respostas referem que desenvolvem uma vivência profissional em laboratorio onde os alunos "apresentam um relatório a partir de uma reflexão teoria/ prática”. "Os alunos expõem suas atividades que são analisadas segundo um referencial teórico."

Quatro (4) professores realizam a relação teoria x prática mediante estudos de caso "tendo o referencial teórico como fundamentação da ação dos alunos."

Cabe ressaltar que quatro professores entendem que a relação teoria/ prática só se faz presente no estágio quando esta ocorre no decorrer de todo 
o curso, evidenciando um compreensão do estágio como parte integrante do processo de formação.

\section{Quado 6 - Influência dos estágios nas mudanças de con teúdo pogramático dos cursos}

\begin{tabular}{|l|c|}
\hline JUSTIFICATIVA & No \\
\hline $\begin{array}{l}\text { Retroalimentação constante por meio de reuniões, leituras, } \\
\text { autoavaliação com os alunos, relatórios, feed-back em grupo }\end{array}$ & 28 \\
$\begin{array}{l}\text { Adaptação dos conteúdos conforme exigências dos } \\
\text { campos de estágio }\end{array}$ & 8 \\
Replanejamento do estágio & 8 \\
$\begin{array}{l}\text { Trabalho interdisciplinar } \\
\text { Observação das dificuldades dos alunos frente as } \\
\text { situações específicas }\end{array}$ & 6 \\
Recuperação dos conteúdos & 4 \\
\hline TOTAL & 2 \\
\hline
\end{tabular}

Dos professores supervisores respondentes vinte e oito (28) deles realizam a retroalimentação constante por meio de reuniões, leituras, relatórios e auto-avaliação o que é utilizado para o replanejamento dos estágios e reavaliação dos conteúdos trabalhados no curso e ainda para adaptar o conteúdo às exigências do mercado 


\section{B - Diatrizes Institucionais}

Quado 7 - Dificuldades encontradas no está gio segundo os professoes

\begin{tabular}{|l|c|}
\hline DIFICULDADES & N. $^{{ }^{\mathbf{2}}}$ \\
\hline Reorganização curricular inadequada & 26 \\
Excesso de alunos por turma & 23 \\
Ausência de convênios & 18 \\
Falta de conhecimento teórico/prático & 15 \\
Insegurança de atuação dos alunos no campo & 11 \\
Campos de estágio não atendem às necessidades de & 11 \\
profissionalização & 10 \\
Dificuldades no relacionamento interpessoal & 7 \\
Desinteresse dos alunos & 6 \\
Falta de recursos materiais e instrumentais para a prática & 3 \\
Utilização de metodologia tradicional & 3 \\
Ausência de integração entre Universidade e & \\
campo de estágio & 2 \\
Atividades de pesquisa sem resultados que promovam & 2 \\
a melhoria do curso & 1 \\
Horário incompatível com as possibilidades dos alunos & $\mathbf{1 3 7}$ \\
Ausência de entrosamento de professores & \\
\hline TOTAL & 2 \\
\hline
\end{tabular}


Verificou-se dentre as respostas dos professores supervisores que vinte e seis (26) identificaram necessidade de reorganização curricular e vinte e três (23) professores indicaram que há um número excessivo de alunos por turma.

Onze (11) professores percebem insegurança do aluno em sua atuação em campo de estágio. Dezoito (18) deles identificaram a necessidade de a universidade estabelecer convênios para assegurar os campos de estágio aos alunos. Onze (11) professores informaram que o campo de estágio não atende às necessidades de profissionalização dos mesmos. As demais dificuldades se referem à falta de recursos materiais e instrumentais para a prática, inadequação de espaço físico e/ ou campos de estágio, falta de interesse dos alunos, atividades de pesquisa sem resultados que promovam a melhoria do curso, entre outras. Evidenciam-se tanto dificuldades que decorrem da concepção pedagógica do curso como as que decorrem da ausência de uma efetiva política de estágios por parte da instituição.

\section{Discussão}

\subsection{Dados obtidos junto astdins de curso}

Os resultados obtidos junto aos Diretores deixam evidente a importância de estudos e discussões sobre os estágios curriculares no âmbito da Instituição. A constatação de que $20.84 \%$ dos Cursos não ofertam estágio curricular é preocupante, pois, não estão sendo propiciadas ao aluno vivências em ambiente real de trabalho o qual oportuniza um aprendizado fundamental para sua vida profissional. Outro dado que merece ser ressaltado é o número de horas destinadas aos estágios. Verifica-se que a carga horária é mínima não chegando em grande parte dos cursos a $5 \%$ da carga horária total do curso e ainda na sua grande maioria ofertados a partir do 70 período.

Aumentar a carga horária destinada aos estágios é uma reivindicação de professores e alunos conforme indica Pimenta: " $\{. .$.$\} não tem sido raro$ professores e alunos clamarem por mais pratica, uma vez que consideram os cursos muito teóricos. As aspirações por mais prática freqüentemente tem sido direcionadas ao estágio supervisionado" (1997, p. 11 ).

A realidade traz elementos importantes para reflexão e estes elementos devem ser aproveitados para que o aluno possa instrumentalizar-se para uma leitura crítica da realidade, identificando os problemas e os desafios para intervenção (Gisi; Schuartz, 1999).

Os diretores consideram que de fato a carga horária destinada aos estágios é insuficiente para atender tanto as exigências do campo de estágio como as relacionadas à formação acadêmica, até porque os estágios muito 
breves não possibilitam ao aluno uma visão geral da profissão e inviabilizam o desenvolvimento de projetos de intervenção.

Ainda em relação aos dados obtidos junto aos Diretores de Curso constatou-se que estes consideram o estágio como um importante instrumento para reavaliar o processo pedagógico do curso como um todo, pois, permite confrontar a formação acadêmica com o exercício da profissão na qual se irá atuar possibilitando avaliar se o processo educativo proposto promove a formação de profissionais competentes.

\subsection{Dados obtidos junto aosfessoes supervises de está gio}

Os professores supervisores na sua grande maioria, da mesma forma que os Diretores de Curso, consideram que a carga horária destinada aos estágios não é suficiente para vivenciar a realidade. Quando se referem à vivência da realidade estão considerando experiências de aprendizagem diversificadas tais como: acompanhar todo o processo de uma determinada atividade ou cumprir todas etapas de um projeto de estágio ou ainda discutir e analisar casos clínico como ocorre na área da saúde.

Quando perguntados se o estágio propicia a visão do cotidiano profissional os professores na sua maioria consideram que o etságio favorece a relação teoria/prática e permite visão ampla do cotidiano profissional. No entanto, algumas respostas referem que os campos de estágio são muito restritos não possibilitando uma visão abrangente do ambiente profissional ou ainda porque a carga horária insuficiente não possibilita tal visão.

Sobre a orientação inicial feita pelos professores supervisores aos alunos estagiários constata-se que a maioria refere-se ao planejamento prévio do estágio indicando ainda que é feita apresentação de normas e da legislação aos estagiários.

Luck considera que na maioria das vezes o problema relacionado aos estágios não se encontra na sua programação mas no efetivo acompanhamento do estagiário que fica "à mercê da sorte". De acordo com esta autora os professores não estão preparados para acompanhar os estágios, que ficam restritos ao contexto imediatista do trabalho e não desenvolvendo compreensão global do mesmo (Lück, 1995, p.21).

Ocorre também falta de planejamento dos estágios conforme indica Moisés (1993) que assim se pronunciou no 2ํㅡㄹ Encontro Estadual de Estágios realizado em Curitiba: Os planos muitas vezes são confusos e referem-se a atividades inexeqüíveis ou incoerentes com os objetivos a serem alcançados. Os objetivos, por sua vez, muitas vezes são do serviço não identificando aqueles relativos ao aprendizado do aluno ou propõem atividades que demonstram que o professor não conhecia bem o serviço. 
A maioria dos professores refere que o aluno faz o planejamento ou projeto de estágio como instrumento orientador das atividades a serem realizadas no campo. No entanto, várias respostas indicam que os alunos não elaboram um projeto de estágio, o que deixa evidente que o planejamento não constitui preocupação em muitos cursos.

A relação teoria/prática de acordo com os professores ocorre mediante realização de reuniões, estudo de casos, pesquisas e seminários. Vários professores afirmaram que ocorre a relação teoria/prática mas não explicitaram de que forma. O importante é que os professores entendam que o estágio não pode ser entendido como momento de aplicação da teoria mas " $\{. .$.$\} sim a$ explicitação da indissociabilidade da interação teoria/prática" (Marchi, 1997, p.16). Nesta perspectiva o estágio jamais poderá assumir o caráter de complementaridade.

Outro aspecto de fundamental importância refere-se ao estágio propiciar a reavaliação curricular. Isto de acordo com a maioria dos professores ocorre no que se refere a adequação de conteúdos à realidade dos campos de estágio, na atualização de conhecimentos por meio de reuniões e avaliações feitas pelos alunos bem como pelos relatórios de estágio.

Em relação as dificuldades apontadas pelos professores verifica-se que são inúmeras e podem-se destacar: a organização curricular inadequada, o reduzido número de professores supervisores de estágio, a não efetivação de maior número de convênios, a desmotivação dos alunos e a falta de material no campo para o desenvolvimento das atividades. Tais dificuldades se não forem sanadas prejudicam o desenvolvimento do estágio e não se favorece a aquisição das competências pelos alunos.

\section{Considerações Fina is}

A fase da pesquisa relativa ao diagnóstico dos estágios curriculares que ora apresentamos indica que o seu estudo foi de fundamental importância pois possibilitou o conhecimento da realidade. A intenção é dar continuidade a este processo investigativo mediante realização de seminários que possibilitem uma efetiva transformação na concepção, organização e planejamento dos estágios curriculares na Instituição.

Os Cursos encontram-se, neste momento, em fase de implantação dos novos projetos pedagógicos e certamente já ocorreram mudanças quanto a oferta dos estágios. No entanto, as dificuldades e as lacunas percebidas não são transformadas apenas com aumento da carga horária ou a sua oferta no decorrer do curso. É necessário que o estágio realmente atenda as exigências de formação para as necessidades colocadas pela sociedade atual. 
Nesta perspectiva o estágio deve ser motivo de constantes análises para que venha constituir-se em espaço propício para a formação de profissionais capazes de intervir e transformar a sociedade. Sua importância é incontestável e hoje mais do que em qualquer época o estágio se apresenta como fundamental, o que pode ser constatado na LDB (Lei no 9394/96) quando indica que a Educação deverá postular-se ao mundo do trabalho e á prática social numa correlação entre cidadania e trabalho. Para atingir tal propósito os estágios se apresentam como o espaço privilegiado de aprendizagem.

\section{Referências Bibliográficas}

BARBIER, R. Pesquisa ação na instituição educacional. Rio de Janeiro: Zahar, 1985

BASTOS, Cleverson KELER, Vicente. Aprendendo a aprender: Introdução à Metodologia Científica. 10ํo ed. Petrópolis: Vozes, 1998

CUNHA, Maria Izabel. O bom professor e sua Prática. Campinas : Cortez, 1998

DELORS, JackeS. Educação: Um tesouro a descobrir. 3a ed. São Paulo : Cortez, 1999

GISI, Maria de Lourdes; SCHUARTZ, Maria Antonia. Estágios Curriculares: Concepção e organização. Caderno de Pós-Graduação em Educação. Apontamentos 3. Ano 1. Curitiba: PUCPR,1999

LUDKE, Menga. A pesquisa na prática e na formação dos professores. Texto apresentado no VI Encontro de Didática e Prática de Ensino. Porto Alegre,1991

LUCK, Heloisa. Qualidade total no estágio. ANAIS...III Encontro Estadual de Estágios, 13 a 14 de novembro de 1995. Curitiba: UFPR/Coordenação geral de estágios, Curitiba,1995

MOISÉS, Samuel Jorge. Relatório dos estágios ocorridos no período de janeiro a julho de 1993 na Secretaria Municipal da Saúde de Curitiba. ANAIS...II, Encontro Estadual de Estágios. Curitiba: UFPR/Coordenação Geral de Estágios, 1993

MARCONI, Maria de Andrade; LAKATOS, Eva Maria. Técnicas de pesquisa: planejamento e execução de pesquisas, amostragens e técnicas de pesquisa, elaboração, análise e interpretação de dados. 4⿳亠丷a ed, São Paulo: Atlas, 1994 
MARCHI, Euclides. Palestra de abertura do I Encontro Nacional de Estágios. ANAIS do I Encontro Nacional de Estágios: Aspectos éticos e legais; de 25 a 28 de agosto de 1997. Curitiba: UFPR/Coordenadoria Geral de Estágios, 1997

NÓVOA, A (org.) As organizações escolares em análise. Portugal: Dom Quixote, 1992

PIMENTA, S. G. O estágio na formação dos professores: Unidade teoria e prática. 3a ed. São Paulo : Cortez, 1997

SALGADO, João. Os estágios e o processo de construção da ética e da cidadania. ANAIS..II Encontro Estadual de Estágios de 15 a 17 de setembro de 1993,. Curitiba: UFPR/Coordenadoria geral de Estágios, 1993 